\title{
Peertechz
}

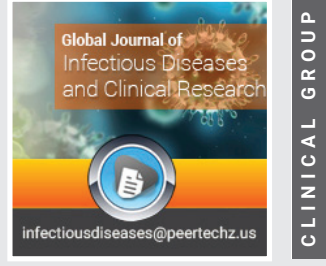

\section{Factors promoting}

\section{schistosomiasis infection in}

endemic rural communities

of Ifedore and Ile-Oluji/Oke

Igbo local government areas in Ondo State, Nigeria

\author{
Adeneye $\mathrm{AK}^{1 *}$, Sulyman $\mathrm{MA}^{1}$, Akande $\mathrm{DO}^{2}$ and Mafe $\mathrm{MA}^{1}$ \\ 'Department of Public Health and Epidemiology, Nigerian Institute of Medical Research, Yaba, Lagos, \\ Nigeria
}

${ }^{2}$ Clinical Diagnostic Laboratory, Nigerian Institute of Medical Research, Yaba, Lagos, Nigeria

Received: 29 March, 2021

Accepted: 14 April, 2021

Published: 15 April, 2021

*Corresponding author: Adeneye AK, Department of Public Health and Epidemiology, Nigerian Institute of Medical Research, Yaba, Lagos, Nigeria, Tel: +234-805788-7698; E-mail: oakadeneye@yahoo.co.uk

Keywords: Schistosomiasis; Knowledge; Perception; Praziquantel; Prevention; Treatment; Rural communities; Nigeria

https://www.peertechzpublications.com

Check for updates

\begin{abstract}
Schistosomiasis, a chronic parasitic disease, is highly endemic in Nigeria and causes severe morbidity among school children in many poor-resource communities in the country. We investigated the factors that promote schistosomiasis infection in rural hyper-endemic communities of two LGAs in Ondo State, South West Nigeria. Data were collected through a household survey, focus group discussions, indepth interviews, key informant interviews among different categories of stakeholders in schistosomiasis control that include community adult members, school pupils, health workers and disease control officers. The quantitative and qualitative data were analysed using the Epi Info (version 6.04a) and Textbase Beta software respectively. A large number (71.1\%) of respondents described schistosomiasis as a prevalent infection in their communities and $34.6 \%$ reported having a member of their households who was infected with schistosomiasis. The LGA of residence of the respondents significantly influenced the respondents' perception of the seriousness of the consequences of the disease as more respondents in lle-Oluji/Oke Igbo LGA perceived it to be a very serious health problem than those in Ifedore LGA [27.8\% Ile-Oluji/Oke Igbo LGA vs. $5.9 \%$ Ifedore LGA] ( $<<0.05)$. The results show that communities in the LGAs are endemic of schistosomiasis mainly because the people have little or no access to safe potable water thereby increasing their rate of contact with natural flowing streams, ponds and or rivers which are or may be infested with susceptible snail intermediate hosts for domestic and occupational activities as about $52 \%$ of respondents admitted going to the stream/river. Other factors the study revealed to aid the prevalence of schistosomiasis in the communities is lack of political will and commitment to effective schistosomiasis control and eradication by the government. There was also evidence of community involvement and participation in schistosomiasis control in only one of the four communities studied. To eliminate schistosomiasis in the communities, efforts need to be made and sustained by the government at all levels to ensure increased political will with more community involvement and participation to achieve effective schistosomiasis control.
\end{abstract}

\section{Introduction}

Schistosomiasis is one of the most prevalent Neglected Tropical Diseases (NTDs) [1] and is a disease of public health and socio-economic importance considered the most devastating parasitic disease in tropical countries [2]. Schistosomiasis is caused by infection with trematodes of the genus Schistosoma whose intermediate host is the freshwater snail, the Bulinus snail species. Schistosoma haematobium mostly in Africa causes genito-urinary schistosomiasis, while intestinal schistosomiasis is caused by Schistosoma mansoni and Schistosoma japanicum [1]. Schistosoma intercalatum ilargely identified in inhabitants and immigrants from West Africa is genetically thought to cause both intestinal and genito-urinary schistosomiasis [3].

An estimated 200 million people are infected and 700 million at risk, mostly in developing world particularly subSaharan Africa $[2,4,5]$. The estimated population at risk of morbidity in the African region is 214 million and those at risk 
of infection, 582 million [6]. These figures, for Nigeria are 35 million and 121 million respectively and the country by these figures lead in terms of burden of the disease in the region among the 10 highly infected countries that included Malawi, Ethiopia and Nigeria. According to Chitsulo, et al. [7], an estimated 101 million Nigerians need treatment.

The high prevalence of schistosomiasis infection is closely correlated with poverty, poor personal and environmental hygiene and poor health services and awareness. Effort at improving hygiene and prevention of the disease will contribute to reducing both the disease and poverty since poor hygienic conditions are underlying cause of most parasitic diseases and of poverty-related infectious diseases in general. In most endemic areas, highest prevalence and intensities of infection are found in school-aged children (6-15 years) although high risk groups include not only school-aged children (including non-enrolled), but also adolescents and young adults, women of child bearing age and others which include those who are occupationally at risk [5].

Morbidity due to schistosome infection is expressed as impaired growth, physical fitness, activity and reduced cognitive development. Blood loss due to schistosomiasis leads to iron deficiency and anaemia may be precipitated. Poor iron status and iron deficiency anaemia are closely linked to diminished educational performance. The severity and complexity of the pathology of schistosomiasis are related to the fate of the eggs that become trapped in the tissues. It has been shown that treatment with praziquantel drug causes worm burden to fall significantly after single oral dose and reverses the morbidity. Reversal of organ damage follows 6 months after cure of urinary schistosomiasis although resurgence can occur after another 6 months. Intestinal schistosomiasis regresses promptly after treatment and regression of periportal fibrosis and subsequent resurgence (as detected by ultrasonography) occur between 7 months and several years after cure. Quantitative improvements in periportal fibrosis, hepatomegaly and splenomegaly have been reported [8] as well as improvement in physical fitness, appetite and school performance. Deterioration in iron status is arrested by treatment and iron supplementation improves iron status in school children, as shown in Tanzania.

Although there is no current estimate for the disease in Nigeria, past estimates have calculated infection rates of about 25 to 29 million people and 101 million at risk of infection $[7,9]$. Epidemiological studies in many endemic communities in Nigeria reported the infection in all the geographical zones of the country, particularly among the children of school age [10]. Many factors including routine agricultural practices, human behaviour, and water projects to meet the needs of people have attributed to sustained schistosomiasis infection in many endemic communities of the country [10].

Historically, Nigeria set up a National Schistosomiasis Control Program in 1988 which aside from conducting the 1991/1992 national prevalence survey on the disease [11] has not recorded any significant achievement as a result of poor funding and lack of free donation of the drug praziquantel for the disease control. Control of other neglected Tropical Diseases
(NTDs) such as onchocerciasis, guinea worm and lymphatic filariasis have been made possible through free donation of the needed drugs for either mass or targeted treatment. The nonfree donation of praziquantel, the drug of choice in the control of schistosomiasis has been a major impediment to the disease control in many developing countries such as Nigeria. Despite several reports on high level of endemicity of schistosomiasis in Nigeria, its control has been greatly hindered by finance and lack of free donation of the drug and this will continue to be a challenge unless adequate funding is provided for the control program. Even when the drug is donated free, program operation costs need to be met. It is therefore not only important to secure and ensure adequate donation of supplies but needed program budget must be provided for effective control. Baseline data need to be collected to develop Geographic Information System (GIS) map on the disease that will guide choice of treatment strategy and approach and, monitoring and evaluating impact of interventions. The Federal Ministry has recorded a milestone in its current attraction of free donation of praziquantel to Nigeria through WHO Geneva from E Merck Germany [12]. The two States that benefitted from this first free supply of the drug in 2009 were Ekiti, and Ondo States in South West Nigeria.

The big study on which this paper is based was an applied and operational health systems research in support of primary health care programs to strengthen and support State's control efforts, seeking to establish close partnership with States in South West Nigeria undertaking schistosomiasis control to ensure that appropriate strategy and approach are employed in the control of the disease and to generate scientific evidence on the process, impact and benefits of the control efforts while documenting the deficiencies that will inform future improvement. The study also sought to garner scientific evidence on the effects of praziquantel on other intestinal parasites which has implications for the current government's commitment to triple drug administration for integrated control of common and prevalent diseases that affect the growing child (albendazole and ivermectin for lymphatic filariasis, ivermectin for onchocerciasis control and praziquantel for schistosomiasis). The focus of this paper is on the social aspects of the disease addressing the knowledge, attitude, practices on cause, transmission, manifestation and treatment and other interventions for schistosomiasis control to reveal risk factors promoting the infection in high schistosomiasis endemic communities.

\section{Methods}

\section{Study design and locations}

The sub-study on which the focus of this paper hinges was cross sectional. The study was conducted in rural communities of Ifedore (Ipogun and Bolorunduro) and Ile-Oluji/Okeigbo (Ile-Oluji and Oke Igbo) local government areas (LGAs) in Ondo State, South West Nigeria (Figure 1). The two LGAs are located between latitude $7^{\circ} 00^{\prime} \mathrm{N}$ and longitude $5^{\circ} 30^{\prime} \mathrm{E}$ and latitude $5^{\circ}$ $00^{/} \mathrm{N}$ and, latitude $7^{\circ} 30^{\prime} \mathrm{E}$ respectively. Ifedore and Ile-Oluji/ Oke Igbo LGA each has a 2020 projected population of 212,304 and 207,349 people respectively based on the 2006 National 


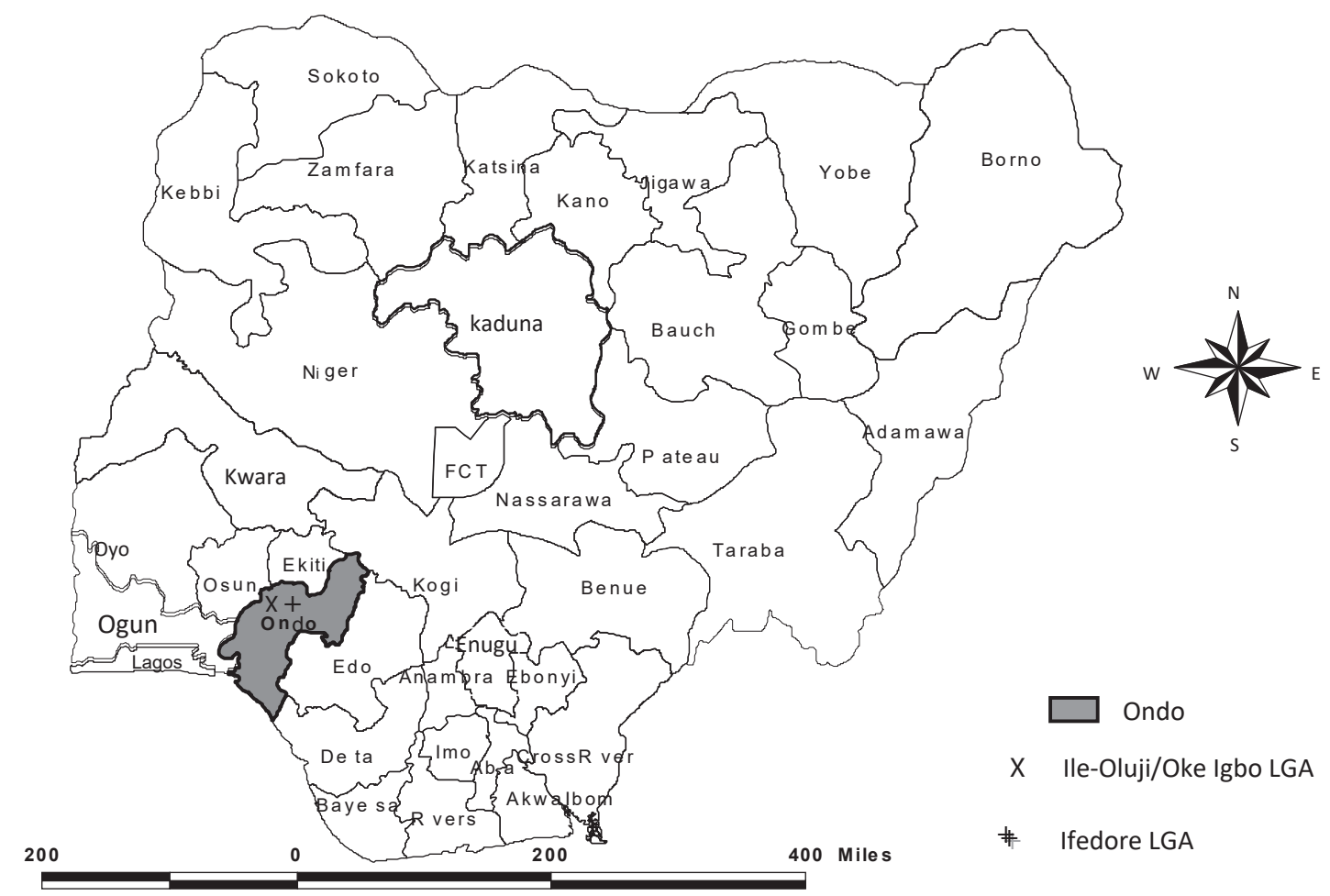

Figure 1: Map of Nigeria showing Ondo State, in which the study LGAs are spotted.

Population Census at $3.5 \%$ growth rate [13]. High prevalence rates of between $41.0 \%$ and $95.7 \%$ have been reported for these LGAs [14-16]. The two LGAs fall within the tropical forest zone of western Nigeria which is characterized by rainfall season from April to October with a short break in August. There are many surface water bodies used for different purposes varying from recreational, domestic, processing of farm produce, bathing, and occupational [17]. The main water sources in IleOluji/ Oke Igbo LGAs include Olori and Ojege rivers. Public tap water points exist but are usually dry in the dry season. Aponmu and Owena rivers are the major water sources in Ifedore LGA. Boreholes are also available in these LGAs but the long waiting time discourages use with preference for the rivers. Sanitation is generally poor and human and animal wastes are disposed of indiscriminately.

\section{Study population}

Target populations for the study were primary school children, school teachers, health workers at the local government (Schistosomiasis Control Programme Coordinators), health workers of health facilities closest to the study communities and adult community members.

\section{Sample size and sampling procedures}

Selection of Ondo State was guided by its inclusion as one of the beneficiaries of the first free supply of praziquantel by Federal Ministry of Health based on provision of required and essential baseline data on the disease by the State. Purposive sampling was employed in the selection of the LGAs with emphasis on those with highest endemicity in the State. Two communities were subsequently selected in each LGA using random sampling to ensure representativeness of the sample.

A sample size of 51 was calculated but approximated to 52 using the table for a minimum sample size estimate for a population survey with $95 \%$ confidence interval using the formula: [18] where $\mathrm{n}=$ sample size, $\mathrm{Z}=1.96, \mathrm{p}=0.95, \mathrm{~d}=$ 0.06 .

$$
\begin{aligned}
& \mathrm{n}=\frac{\mathrm{Z}^{2}[\mathrm{p}(1-\mathrm{p})]}{\mathrm{d}^{2}} \\
& \mathrm{n}=\frac{1.96^{2}[0.95(1-0.95 \mathrm{p})]}{0.06^{2}}
\end{aligned}
$$

\section{Data collection procedure}

In addition to the parasitological examinations in other arm of the bigger study though not reported in this paper, Focus Group Discussions (FGDs), Indepth Interviews (IDIs), Key Informant Interviews (KIIs) and household survey were conducted using FGD, IDI and KII guides and questionnaire respectively.

A total of eight FGD sessions were held among male and female primary school pupils, as well as male and female adult members of the communities in selected LGAs. Each FGD session was ensured to comprise a minimum of seven participants of same gender with similar social background. The IDIs were held with three teachers, three health workers of health facilities closest to the study communities, and the KIIs were conducted among Schistosomiasis Control Programme Coordinators of the two LGAs studied. 
The household survey involved the administration of semistructured questionnaires to adult members of the communities proving their knowledge and perception of the cause, signs and symptoms, perceived severity of schistosomiasis and treatment options available for the disease. Probing questions on sources of water for drinking and other household use and how domestic and human wastes are disposed were be posed as well as on knowledge of praziquantel as the drug of choice for schistosomiasis treatment alongside the frequency of its mass administration for control in the communities as well as challenges, if any. Respondents were further probed on their willingness to pay for schistosomiasis treatment using praziquantel and the extent to which community efforts will contribute to the control of schistosomiasis in the study communities.

The contents of the interview and FGD guides like the questionnaires sought to generate information relating to the prevalence and incidence of schistosomiasis in the communities, the knowledge of the pupils and adults alike about the cause, signs and symptoms, perceived severity of the infection, treatment options available for the disease and the extent to which community efforts have contributed to the control of schistosomiasis in the study communities was similarly probed. Probing questions mirrored those in the administered questionnaire.

In addition to the above, the Schistosomiasis Control Programme Coordinators, health workers and teachers trained for the mass treatment exercise in the study LGAs were asked questions relating to the contents of training they had. The issues probed using the interview and FGD guides included: cause of the infection, prevention, record keeping as it concerns basic socio-demographic information of those to be treated and number of drugs supplied and dispensed, dose determination and tool to use in achieving this, target population, and strategy to adopted for the mass treatment and how out-ofschool children in the communities will be reached.

\section{Data analysis}

Following data cleaning, the completed questionnaires were coded. The coded data were subsequently entered into the computer and analysed using the Epi Info (version 6.04a) software [19]. The analysis was essentially descriptive reflecting the concerns expressed through the different objectives of the study.

On the other hand, following review and correction, transcripts from the FGDs and in-depth interviews were typed with a standard word processing package and converted into ASCII Text files. These were subsequently coded and sorted using the textual analysis programme developed by Bo Summerlund and distributed by Qualitative Research Management of Desert Hot Springs, California, Textbase Beta software [20,21].

\section{Ethical issues}

All necessary approvals were obtained from the State Ministry of Health, the selected LGAs and communities. Ethical approval for the study protocol was obtained from the Nigerian
Institute of Medical Research Institutional Review Board. Informed consent of each adult participant and the parents/ caregivers of each child participant was duly obtained prior to their enrolment in the study as an indicator of their willingness to participate in the study. The informed consent process involved careful explanation of the purpose and procedure of the study, the potential benefits (both individual and community) and possible risks of participating in the study.

\section{Limitations of the study}

The main limitation of this study is the non-evaluation of the respondents' actual willingness to pay for praziquantel as the recommended drug of choice for treatment. Another limitation of this study is the small sample size used to generate the quantitative data from the survey arm of the study in the two LGAs studied in Ondo State. The sample size is though anticipated to be adequate having used the table for a minimum sample size estimate for a population survey. Nonetheless, this limitation does not underestimate the validity of the findings of this study as the findings from the small sample size are complemented by the findings from qualitative data.

\section{Result}

\section{Socio-demographic background of respondents}

Of the fifty-two respondents interviewed in the household survey, thirty-four $(65.4 \%)$ were from Ifedore LGA while eighteen $(34.6 \%)$ were from Ile-Oluji/Oke Igbo LGA. Gender distribution of the respondents showed that $51.9 \%$ and $48.1 \%$ were males and females respectively. The ages of the respondents in the household survey ranged from 20 to 70 years with an average age of 38.4 years and a median of 36 years. Most $(90.4 \%)$ of the respondents were married while only $9.6 \%$ were never married.

A large number (90.4\%) of them were Christians and 9.6\% were of the Islamic faith. More than $60.0 \%$ of the respondents were engaged in the informal sector. Their occupational distribution showed that most $(28.8 \%)$ were traders while $21.2 \%$ were farmers and artisans respectively. Others were civil servants $(19.2 \%)$, students $3.8 \%)$; security guards (3.8\%); and housewives $(1.9 \%)$. The level of literacy reported among the respondents interviewed was very high as about $45.0 \%$ had a minimum of secondary education. Their levels of educational attainment were: primary (53.8\%); secondary (34.6\%); and post-secondary (11.5\%).

\section{Knowledge and perceived public health significance of schistosomiasis in the community}

There was a high level of awareness of schistosomiasis disease in the communities studied as displayed in Figure 2 and attested to by participants in the series of FGDs conducted.

A larger number $(42.3 \%)$ of respondents described the disease as common while $28.8 \%$ believed it is very common and $23.1 \%$ said it is not common in their respective localities. Only $3.8 \%$ were indifferent on the perceived prevalence of the disease in their communities. 


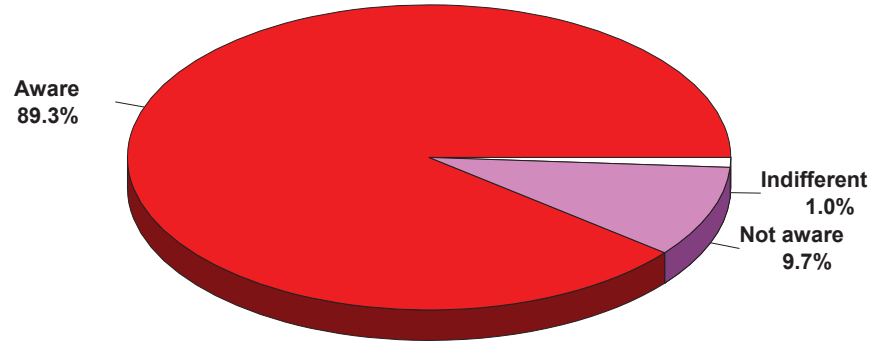

Figure 2: Awareness of cases of schistosomiasis infection in the community among respondents.

Results further showed that all the focus group participants and those interviewed in the communities mentioned schistosomiasis as a predominant disease next to malaria and measles in their respective neighbourhood. The Ifedore LGA Schistosomiasis Control Programme Coordinator for example pointed out that, "The LGA is very endemic with the infection in three communities: Ipogun, Irese and Owena-Bolorunduro which happens to be the most endemic." A male focus group participant in Oke Igbo similarly revealed that, "In our community, we have the problem of malaria and schistosomiasis." The Ile-Oluji/Oke Igbo LGA Schistosomiasis Control Programme Coordinator also affirmed the high prevalence of the infection in communities of the LGA stating that, “...During a recent survey, results showed that the LGA had a prevalence rate of over 90 percent, next to Ifedore LGA in the State".

Of the fifty-two respondents interviewed, only eighteen $(34.6 \%)$ reported that they had a member of their household who was infected with schistosomiasis while $65.4 \%$ claimed they had no one infected with the disease in their household. The number of household members infected with schistosomiasis mentioned ranged from one to four with an average of two household members.

Schistosomiasis is perceived to be a serious health problem by many respondents in the household survey as presented in Table 1. The LGA of residence of the respondents significantly influenced the respondents' perception of the seriousness of the consequences of the disease as more respondents in IleOluji/Oke Igbo LGA perceived it to be a very serious health problem than those in Ifedore LGA [27.8\% Ile-Oluji/Oke Igbo LGA vs. $5.9 \%$ Ifedore LGA] just as no respondent perceived it as not a serious health problem in the former compared to a few who did in the latter [0\% Ile-Oluji/Oke Igbo LGA vs. $14.5 \%$ Ifedore LGA] $\left(\chi^{2}=8.43, \mathrm{df}=3, \mathrm{p}<0.05\right)$.

Similarly, FGD participants in the communities believed it is a life threatening disease because it involves the loss of blood from the body through urination. This reflected in the response of a female focus group participant in Oke Igbo, Ile-Oluji/Oke Igbo LGA, who said, "...when these children have the infection, they usually look pale and complain of high body temperature and passing of blood in urine. It is a serious infection that can threaten life."

Unfortunately, however, a few FGD participants were concerned that some parents do not usually take steps to ensure treatment. A male teacher in Oke Igbo, Ile-Oluji/Oke Igbo LGA, pointed out thus: "...It is sad that many parents and guardians are less concerned about this problem (schistosomiasis) in their children because they don't take it seriously as it ought to be."

\section{Perceived at-risk groups of the disease among respon- dents}

The illustration in Figure 3 shows that children of primary school age of ten years and below were perceived to be the age group most at risk of the infection in the study communities. The reasons given by the respondents for their choice of perceived at-risk age group were: because they like swimming in the river as an art of recreation (71.2\%); and going to fetch water at river side (1.9\%). However, about $27.0 \%$ were undecided on the reason to give to justify their choice of their perceived at-risk age group.

Statistical test showed gender difference in the respondents' perceived most at-risk group of schistosomiasis as more males than females perceived children aged ten years and below as the age group most at risk of the infection (96.3\% males vs. $56.0 \%$ females). The odds ratio of 0.05 has a $95 \%$ confidence interval of $0.00-0.45$, and chi square with Yates correction is 9.71 with a $\mathrm{p}$-value $<0.05$

Similarly, it was a consensus among virtually all the FGD participants in the communities that the infection is predominant mostly among children of school age, though many adults were also reported to have manifested the main sign of the disease i.e. passing of blood in urine. A male focus group participant in Oke Igbo, Ile-Oluji/Oke Igbo LGA, for example said, "Children and, even adults, pass blood in urine." Another male focus group participant in Oke Igbo, Ile-Oluji/Oke Igbo LGA, pointed out that, "Our children are the most affected with this problem (schistosomiasis) even though some adults of my age still experience same problem." A male teacher interviewed in Oke Igbo, Ile-Oluji/Oke Igbo LGA, also revealed that, "The

Table 1: Perceived seriousness of schistosomiasis as a health problem among respondents.

\begin{tabular}{|c|c|c|c|c|c|c|c|c|c|c|}
\hline \multirow[b]{2}{*}{ LGA } & \multicolumn{2}{|c|}{ Very serious } & \multicolumn{2}{|c|}{ Serious } & \multicolumn{2}{|c|}{ Not serious } & \multicolumn{2}{|c|}{ Indifferent } & \multicolumn{2}{|c|}{ Total } \\
\hline & Number & $\%$ & Number & $\%$ & Number & $\%$ & Number & $\%$ & Number & $\%$ \\
\hline Ifedore & 2 & 5.9 & 24 & 70.6 & 5 & 14.7 & 3 & 8.8 & 34 & 65.4 \\
\hline $\begin{array}{l}\text { Ile-Oluji/ } \\
\text { Oke Igbo }\end{array}$ & 5 & 27.8 & 13 & 72.2 & - & - & - & - & 18 & 34.6 \\
\hline Total & 7 & 13.5 & 37 & 71.2 & 5 & 9.6 & 3 & 5.8 & 52 & 100.0 \\
\hline 90 & 76. & & & & & & & & & \\
\hline 70 & & & & & & & & & & \\
\hline 60 & & & & 48.1 & & & & & & \\
\hline$\stackrel{\rightleftarrows}{\Xi} 50$ & & & & & & & & & & \\
\hline 30 & & & & & & & 9.2 & & 19.2 & \\
\hline 20 & & & & & & & & & & \\
\hline 10 & & & & & & & & & & \\
\hline & $\leq 1$ & & & 1 to 19 & & & -29 & & $30+$ & \\
\hline
\end{tabular}

Figure 3: Perceived most at-risk age group of schistosomiasis by respondent $(n=52)$ 
problem of schistosomiasis is most common among children of school age in this community." A female focus group participant in Oke Igbo, Ile-Oluji/Oke Igbo LGA, similarly said, "The problem (schistosomiaisis) is common among both children and adults. There are many people having the infection in this community."

\section{Recognition of signs and symptoms of the di- sease}

The way most parents know their children are infected with schistosomiasis is when the children's pants become stained with blood or when their siblings or friends report that one of them is passing drops of blood after urination as illustrated in Figure 4 .

\section{Knowledge on transmission route for schistosomiasis}

Figure 5 shows that bathing or swimming in the river is the most perceived transmission route of the schistosomiasis infection among respondents. Similarly, virtually all the FGD participants and the Schistosomiasis Control Programme Coordinators interviewed attributed the high prevalence of schistosomiasis reported in the communities to human contact with the available rivers identified in their respective locality. It was explained that people become infected in the process of collecting or using available source of water (surface water) for domestic, recreational and farming use such as bathing, washing, cooking, drinking and irrigation.

The female focus group participants in Oke Igbo, Ile-Oluji/ Oke Igbo LGA, in a consensus said, "Those who are infected

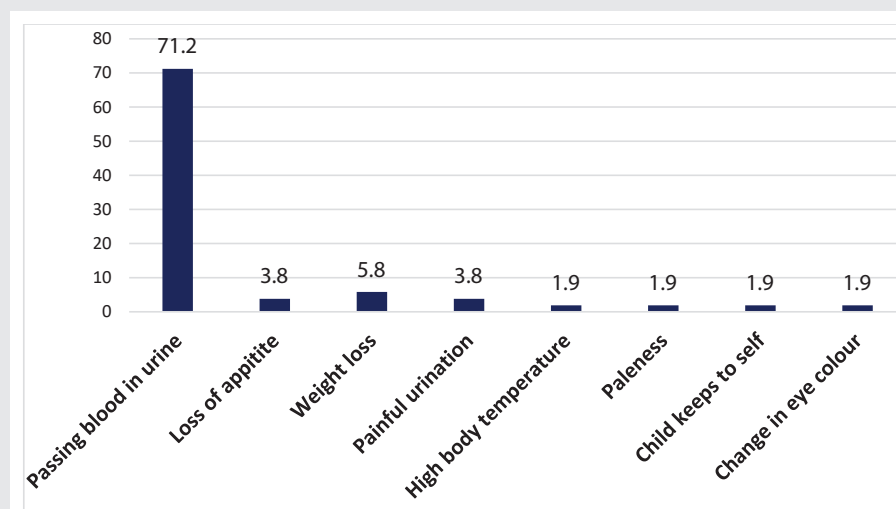

Figure 4: Signs and symptoms of schistosomiasis mentioned by respondents $(n=52)$.

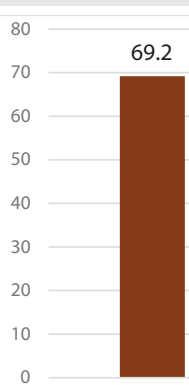

Bathing/swimming in river

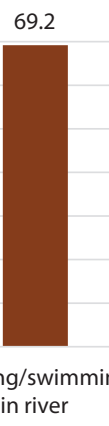

Figure 5: Perceived causes of schistosomiasis among respondents $(n=52)$. with schistosomiasis are mostly those who usually go to Olori River to swim, play and fetch water." A male focus group participant in Oke Igbo, Ile-Oluji/Oke Igbo LGA, similarly said that, "We learnt that the infection is from the river where people usually swim... it is most often reported among those who come in contact with the river." A male teacher interviewed in Oke Igbo, Ile-Oluji/Oke Igbo LGA, pointed out that, "I learnt that the major cause of the infection in this community is the Olori River where many of our children go to swim." A female teacher in Oke Igbo, Ile-Oluji/Oke Igbo LGA, also reported that, "...The Olori River is the main source of water for domestic use in community. As some people go to the river to bath and wash there, others fetch same water to take home for cooking and drinking...I know that some people even urinate and defeacate in the river. It is perhaps because of this poor habit that the water is polluted hence causing the infection to those that go there." Pupils in a focus group in Oke Igbo, Ile-Oluji/Oke Igbo LGA, pointed out that, "We go to Olori River to fetch water for washing. We also play and swim there."

In a series of interviews with school pupils in the communities, most of them regardless of gender attested that they usually swim in the rivers around them. Pupils in Oke Igbo, Ile-Oluji/Oke Igbo LGA, for example reported that, "We all bath and swim in Awoyaya River...some of us go there to wash, fetch water and hunt for crabs." Pupils in Ipogun community, Ifedore LGA, similarly said, "We often go to Aponmu River to fetch water, wash, play and swim...some of us even urinate and defeacate in the river while swimming."

The main justification for why people regardless of age and gender still go to the identified rivers around them despite their knowledge of being predisposed to the infection was that the rivers served as their main source of water for various use.

The persistent patronage of the rivers was attributed to the demand pressure for water because of little or no available safe drinking water from the borehole facilities provided but which have stopped working or is working below capacity in the communities. The challenge of poor terrain for drilling of borehole for safe and reliable water supply was also expressed due to the rocky soil in the area. A male focus group participant in Oke Igbo, Ile-Oluji/Oke Igbo LGA, revealed that, "...the river is our main source of water...there is no well around here because our land is so rocky. We only have access to tap water in the dry season when the public water corporation pumps water for public use." Another male focus group participant in Bolorunduro, Ifedore LGA, pointed out that, "Only one of the two boreholes we have in this community is functional. This has increased the demand on this functional borehole for safe water which has resulted in long queues, and discouraged many people from using the source. Most people have thus resorted to depending on the Owena River for their needs. In recent past, people abandoned the river when the two borehole facilities were functional but things have changed now."

\section{Prevention and treatment practices on schistosomiasis}

The perceived preventive measure against schistosomiasis according to most people, particularly the adults, was said to be avoidance of contact with the rivers. Unfortunately, the communities are challenged by lack of alternative safe and

Citation: Adeneye AK, Sulyman MA, Akande DO, Mafe MA (2021) Factors promoting schistosomiasis infection in endemic rural communities of Ifedore and Ile-Oluji/ Oke Igbo local government areas in Ondo State, Nigeria. Glob J Infect Dis Clin Res 7(1): 021-032. DOI: https://doi.org/10.17352/2455-5363.000042 
reliable source(s) of water for their daily needs. A female focus group participant in Oke Igbo said she believed that "...those who don't have the infection rarely swim in the river."

According to FGD participants in the communities, there are different approaches to treatment of those identified to be infected. Treatment practices mentioned included going to the clinic/hospital, buying drugs from chemist shop and, taking herbal remedies prepared using leaves, barks and roots of trees usually sourced from either the market or home environment.

The different forms of treatment people seek for schistosomiasis in the communities as well as their most preferred form of treatment according to respondents in the household survey are displayed in Table 2 and Figure 6 respectively. Sex of respondents had significant influence on their most preferred form of treatment for schistosomiasis $\left(\chi^{2}\right.$ $=13.17, \mathrm{df}=5, \mathrm{p}<0.05)$.

It is interesting to note that none of the FGD participants knew about praziquantel, the drug of choice used for schistosomiasis treatment. A male focus group participant in Oke Igbo, Ile-Oluji/Oke Igbo LGA, for example said, "I don't know anything about this drug. For example, I'm a carpenter and don't know anything about drug and infections." A female participant in Oke Igbo, Ile-Oluji/Oke Igbo LGA, similarly revealed that, "I don't know the drug that is being used to treat the infection." On the contrary, $23.1 \%$ of respondents in the survey reported knowing about praziquantel.

\section{Community involvement and participation in the control of schistosomiasis}

There was evidence of community involvement and participation in only one of the four communities studied. This was evident in Oke Igbo, Ile Oluji/Oke Igbo LGA through what was reported as the people's involvement in sensitisation and advocacy on control of the disease in their domain. A female

Table 2: Forms of treatment people seek for schistosomiasis in the communities.

\begin{tabular}{|c|c|c|}
\hline Forms of treatment & Number $(\mathbf{n = 5 2})$ & $\%$ \\
\hline Orthodox medicine & 32 & 61.5 \\
\hline Buying drugs from pharmacy/chemist shops & 4 & 7.7 \\
\hline Traditional medicine & 11 & 21.2 \\
\hline Nothing & 3 & 5.8 \\
\hline
\end{tabular}

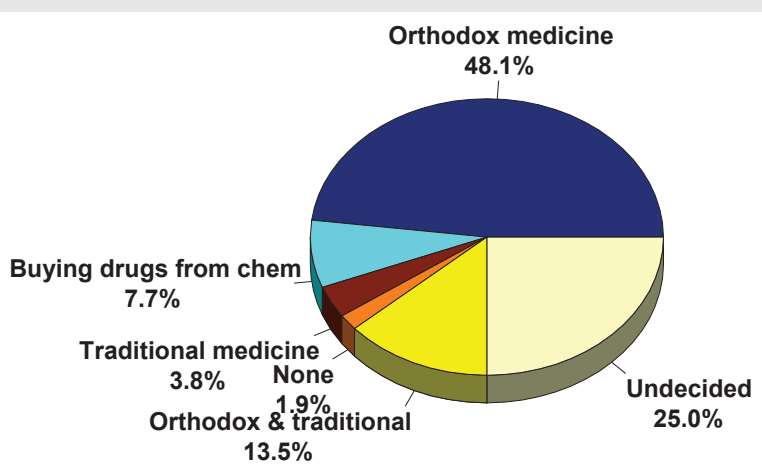

Figure 6: Most preferred form of treatment people seek for schistosmiasis in the communities. focus group in Oke Igbo, Ile-Oluji/Oke Igbo LGA, revealed that, "...the community has been involved in advocacy efforts through the churches and mosques to discourage and advise people particularly children from going to Olori river to swim in order to prevention the infection."

On the contrary, a female focus group participant in Bolunduro, Ifedore LGA, pointed out that, “...I don't know of any programme that has been put in place for implementation to control the infection apart from the programme on immunization that I'm aware of." A male focus group participant in Bolorunduro, Ifedore LGA, similarly revealed that, "...I do not think there are any efforts in this direction at all." Another male focus group participant in Bolorunduro, Ifedore LGA, responded that, "It is not that we do not know what to do but as we are poor farmers, we would only implore the government to come to our aid. We know that we need safe water here but we cannot afford to dig a borehole."

There was evidence of previous mass treatment for schistosomiasis in the communities. Most pupils in focus groups in Ifedore LGA explained that they were treated a year ago whilst some of the pupils in focus groups in Ile-Oluji/Oke Igbo LGA reported that they were treated last three years ago. This was also confirmed by a teacher in Ile-Oluji, Ile-Oluji/Oke Igbo LGA, who stated that, "...children in this school were treated last through mass drug administration three years ago by the local government health workers."

\section{Willingness to pay for schistosomiasis treatment using praziquantel}

Sequel to education on praziquantel and its average cost in treating an infected person related to the participants, all $(100.0 \%)$ respondents in all the communities expressed their willingness to pay for the treatment of infected members of their household with the drug. In the bidding process, most of the participants were willing to pay $\mathrm{N} 80.00(\$ 0.22)$ to $\mathrm{N} 100.00$ (\$0.27) per tablet of the drug and $\$ 320.00$ (\$0.88) to $\$ 400.00$ (\$1.11) per treatment of an infected person. There was no gender difference in the willingness to pay for the treatment of infected household members among the focus groups. The male FGD participants in Bolorunduro, Ifedore LGA, in consensus for example stated that, "...we would be willing to buy the drug for the treatment of the infection at that price you mentioned. All we are interested in is the well being of our children. Of course we would be most willing to pay for the drug as long as we are certain that it is effective."

\section{Training of distributors as one of the indicators of pro- gramme inputs preparatory to mass treatment exercise}

The Schistosomiasis Control Programme Coordinators for the two LGAs have had long years of field experience, ranging from five to twelve years, on schistosomiasis control. The State Ministry of Health (SMoH) was reported to have organized series of training workshops, with the involvement of these officers, on the distribution of the drug, praziquantel. The training workshops are usually held at different times for each of the LGAs in the State but within the same period/season. 
Evidence showed that those trained as distributors usually include school teachers, health workers in public health facilities nearest to the communities concerned and community leaders. On the strategies to be adopted for treatment, the Ifedore LGA Schistosomiasis Control Programme Coordinator stated that, "Teachers and community leaders have been trained. In addition, twenty health workers such as community health extension workers (CHEWs) from the community primary health centres were also trained." The Ile-Oluji/Oke Igbo LGA Schistosomiasis Control Programme Coordinator emphasized that, “...Teachers will help treat all their school children while the health workers were trained to treat all out-of-school children. They were similarly trained to help supervise the teachers involved in the exercise and handle any reported side effects."

In attestation to the strategies, a teacher interviewed in Ipogun, Ifedore LGA, responded that, "We (teachers) were taught to treat only children enrolled in our schools. We learnt that the health workers will treat children who are out of school." A health worker in Ipogun, Ifedore LGA, on the other hand pointed out that, "We (health workers) are to treat those children in the community who are not enrolled in school. We are to also give the drugs to those adults who report at the health centre to complain of the infection. We are not to treat our target population by going from house to house but rather they will come to us at the health centre."

The Schistosomiasis Control Programme Coordinators pointed out that the community leaders were trained in order to enhance community involvement and participation in the treatment exercise. They were enjoined to help sensitise and mobilize parents and guardians to take their out-of-school children to the health facilities for treatment.

On the training components, a trained female teacher interviewed in Ile-Oluji, Ile-Oluji/Oke Igbo LGA, stated that, "We were taught issues relating to the cause of schistosomiasis, its prevention, record keeping with some forms to record basic information about the pupils such as their age, sex, height, number of tablets eligible to a child and remarks based on any observations." She further stressed that, "We were also given a table to use for dose determination. The table comprised height measurements and the corresponding number of tablets to be given." A trained health worker in Oke Igbo, Ile-Oluji/Oke Igbo LGA, similarly pointed out that, "The content of our training included the cause of schistosomiasis, how to prevent it, how to treat with praziquantel using height in determining the appropriate dose and the possible reactions those to take the drug may experience." Another female teacher in Bolorunduro, Ifedore LGA, said, "I was taught the cause of schistosomiasis, its mode of transmission and how to prevent the infection. Further, information relating to how to keep records was provided alongside the consequences of the disease and how to treat affected children using height to determine the appropriate dose."

A health worker in Ipogun, Ifedore LGA, added that, “.. To reach our target population, we have started advocacy and mobilization of people in the community as a way of creating awareness about the availability of the drug praziquantel which they can access for free at the health centre."

\section{Identified challenges of past mass treatment exercise}

Despite the successful take off of the implementation of the mass treatment in the two LGAs amidst the cooperation received so far, some identified challenges militating against the smooth implementation of the exercise included financial constraint, inadequate and delayed drug supply and noninvolvement of many schools in communities of the two LGAs. In the response of the Ifedore LGA Schistosomiasis Control Programme Coordinator, he pointed out that, "The major challenge of the programme is the problem of financial constraint as the local government authority did not support in anyway." This is unlike the authority in Ile-Oluji/Oke Igbo where the Schistosomiasis Control Programme Coordinator said, "The local government authority assisted in the organization of the training exercise and is even enthusiastic in getting more teachers not yet involved to be trained so that more pupils could be treated."

In expressing his concern on the problem of inadequate drug supply, the Ile-Oluji/Oke Igbo LGA Schistosomiasis Control Programme Coordinator revealed that, "Presently, only ten of the available primary schools in the LGA could be covered with the five thousand tablets I collected from the State Ministry of Health. I have already complained to the State Schistosomiasis Control Officer about this inadequacy and will be meeting with her to deliberate on how to get more drug supply that will go round all the schools. Now the children in the LGA will still require about thirty-four thousand tablets for wider and effective coverage through which the nonenrolled children will be covered too."

Similarly, a female teacher in Oke Igbo, Ile-Oluji/Oke Igbo LGA, stated that, "For pupils in this school, I was first given five hundred tablets to use in treating them. However, after exhausting first supply of five hundred tablets and many pupils in the school were not treated, I then requested for additional supply and was given another fifty tablets which would be administered to the outstanding pupils next week."

\section{Household practices in the community relating to water usage and human waste disposal}

When the respondents were asked how they dispose faeces and household wastes such as paper and leaves, most reported using pit latrine $(50.0 \%)$ and throwing/dumping household wastes in the bush $(75.0 \%)$ respectively as presented in Table 3. Respondents' LGA of residence had significant effect on the ways they adopt for the disposal of household waste $\left(\chi^{2}=9.50\right.$, $\mathrm{df}=2, \mathrm{p}<0.05$ ) respectively.

Twenty-seven (51.9\%) of the fifty-two respondents reported going to the streams or rivers around their communities while $48.1 \%$ claimed not going to any of the streams or rivers. Statistical test showed gender difference in the respondents' propensity to go to the stream or river as more males than females are more likely to go to the stream or river $(70.4 \%$ males vs. $32.0 \%$ females) as shown in Table 4 . The odds ratio of 5.05 has a $95 \%$ confidence interval of $1.33-20.04$, and chi square with Yates correction is 6.20 with a p-value $<0.05$. On the contrary, age of respondents had no significant influence the possibility of their going to the river or stream or not $\left(\chi^{2}=\right.$ $0.366, \mathrm{df}=1, \mathrm{p}>0.05$ ). 
Results in Table 5 showed that a larger number $(61.5 \%)$ of the respondents knew that passing of urine or defaecating in the river or stream could contribute to the spread of schistosomiasis. The LGA of residence of the respondents significantly influenced their knowledge that passing of urine or defaecating in the river or stream could contribute to the spread of schistosomiasis $\left(\chi^{2}=7.25, \mathrm{df}=2, \mathrm{p}<0.05\right)$.

\section{Discussion}

The perceived seriousness of schistosomiasis as a health problem by a large number of respondents in LGAs studied in Table 1 confirmed the hyper-endemicity of schistosomiaisis in the two areas of the State.

The findings show that communities in the LGAs are endemic of schistosomiasis mainly because the people have little or no access to safe potable water thereby increasing their rate of contact with natural flowing streams, ponds and or rivers which are or may be infested with susceptible snail intermediate hosts for domestic and occupational activities. Other factors the study revealed to aid the transmission of schistosomiasis in the communities is lack of adequate and appropriate knowledge of the disease among the population studied and lack of political will and commitment to effective schistosomiasis control and eradication by the government.

Table 3: Adopted ways of disposing faeces and household wastes in the communities.

\begin{tabular}{|c|c|c|c|c|c|c|c|c|}
\hline \multirow{3}{*}{ LGA } & \multicolumn{8}{|c|}{ Adopted ways of disposing faeces } \\
\hline & \multicolumn{2}{|c|}{ Pit latrine } & \multicolumn{2}{|c|}{$\begin{array}{l}\text { Number } \% \\
\text { Squat in the bush }\end{array}$} & \multicolumn{2}{|c|}{ Go to the river } & \multicolumn{2}{|c|}{ Total } \\
\hline & Number & $\%$ & Number & $\%$ & Number & $\%$ & Number & $\%$ \\
\hline Ifedore & 13 & 38.2 & 20 & 58.8 & 1 & 2.9 & 34 & 65.4 \\
\hline $\begin{array}{l}\text { Ile Oluji/Oke } \\
\text { Igbo }\end{array}$ & 13 & 72.2 & 4 & 22.2 & 1 & 5.6 & 18 & 34.6 \\
\hline Total & 26 & 50.0 & 24 & 46.2 & 2 & 3.8 & 52 & 100.0 \\
\hline \multicolumn{9}{|c|}{ Adopted ways of disposing household wastes } \\
\hline \multirow{2}{*}{ LGA } & \multicolumn{2}{|c|}{ Burning } & \multicolumn{2}{|c|}{ Dump in the bush } & \multicolumn{2}{|c|}{$\begin{array}{l}\text { Dump in the } \\
\text { river }\end{array}$} & & \\
\hline & Number & $\%$ & Number & $\%$ & Number & $\%$ & Number & $\%$ \\
\hline Ifedore & 4 & 11.8 & 29 & 85.3 & 1 & 2.9 & 34 & 65.4 \\
\hline $\begin{array}{l}\text { Ile Oluji/Oke } \\
\text { Igbo }\end{array}$ & 8 & 44.4 & 10 & 55.6 & - & - & 18 & 34.6 \\
\hline Total & 12 & 23.1 & 39 & 75.0 & 1 & 1.9 & 52 & 100.0 \\
\hline
\end{tabular}

Table 4: Distribution of respondents on whether they go to the stream/river or not.

\begin{tabular}{|c|c|c|c|c|c|c|}
\hline \multirow{2}{*}{ Sex } & \multicolumn{6}{|c|}{ Do you go the stream or river? } \\
\cline { 2 - 7 } & \multicolumn{2}{|c|}{ Yes } & \multicolumn{2}{c|}{ No } & \multicolumn{2}{c|}{ Total } \\
\cline { 2 - 7 } & Number & $\%$ & Number & $\%$ & Number & $\%$ \\
\hline Male & 19 & 70.4 & 8 & 29.6 & 27 & 51.9 \\
\hline Female & 8 & 32.0 & 17 & 68.0 & 25 & 48.1 \\
\hline Total & 27 & 51.9 & 25 & 48.1 & 52 & 100.0 \\
\hline
\end{tabular}

Table 5: Awareness that passing of urine or defaecating in the river or stream could contribute to the spread of schistosomiasis among respondents.

\begin{tabular}{|l|c|l|l|l|l|l|l|l|}
\hline \multirow{2}{*}{ LGA } & \multicolumn{2}{|l|}{ Aware } & \multicolumn{2}{l|}{ Not aware } & \multicolumn{2}{l|}{ Indifferent } & \multicolumn{2}{l|}{ Total } \\
\cline { 2 - 11 } & Number & $\%$ & Number & $\%$ & Number & $\%$ & Number & $\%$ \\
\hline Ifedore & 25 & 73.5 & 7 & 20.6 & 2 & 5.9 & 34 & 65.4 \\
\hline $\begin{array}{l}\text { lle Oluji/Oke } \\
\text { Igbo }\end{array}$ & 7 & 38.9 & 6 & 33.3 & 5 & 27.8 & 18 & 34.6 \\
\hline Total & 32 & 61.5 & 13 & 25.0 & 7 & 13.5 & 52 & 100.0 \\
\hline
\end{tabular}

The results of the study on willingness to pay for praziquantel to treat schistosomiasis are similar to but a higher than the finding of $92.3 \%$ of respondents who expressed willingness to buy the drug for treatment of infected members of their household in a previous household survey that examined the willingness of people to pay for treatment with praziquantel in Imala-Odo, a hyper-endemic community for schistosomiasis in Ogun State, South West Nigeria [22]. In contrast to the observed gender difference reported in the earlier study reported by Adeneye et al [22], there was no gender difference among the population studied in the two LGAs in Ondo State.

One of the limitations of this study earlier stated is the non-evaluation of the respondents' actual willingness to pay for praziquantel as the recommended drug of choice for treatment. The evaluation could have enabled the observation of any possible difference that could be made by the time the reality of the cost of the service actually dawn on the study participants vis-a-vis the household size to be treated, the number of times individuals are to be treated per year, their earnings, and their ability to pay. This could have shown any difference in the hypothetical and actual willingness to pay for the drug by the respondents. Further, the respondents in the Ondo communities may not have revealed their true preferences because of social desirability effects, which could have made them provide answers designed to make them look good to the interviewers as emphasised by Adeneye, et al. [22].

This willingness of people to pay for praziquantel for schistosomiasis treatment examined in the study was with a view to understanding the feasibility of achieving a sustainable universal coverage with praziquantel in the treatment of schistosomiasis which has to be preceded by knowing how people value the drug and estimating the potential market for the drug as indicative in Table 2 where orthodox medicine constituted a large chunk of forms of the pathway to care which the people seek for the treatment of schistosomiasis in the communities and as successfully implemented in a similar previous study by Adeneye, et al. [22]. The high knowledge and good perceptions about the use of praziquantel in the treatment of schistosomiasis in the study communities evident in this study is encouraging. Efforts therefore need to be made to ensure sustainable supply of the drug and at the same time guarantee that all families can afford to pay for praziquantel. This is in order to achieve the ultimate goal of controlling the infection in endemic communities of Nigeria as suggested by Adeneye, et al. [22].

Given that intensified efforts are needed for NTDs including schistosomiasis targeted for eradication or elimination as public health problems by 2030 [23], the implementation of effective measures for interruption of transmission in all endemic communities targeting specific interventions that include provision of safe water, improved access to good sanitation, continuous health education, community mobilization for sustainable involvement and participation and treatment of selected water sources with temephos as recommended by World Health Organisation [24] becomes imperative.

Access to water and sanitation could be improved in the 
communities of the studied LGAs in particular and the State in general through inter-sectoral collaboration between the State Ministry of Health, Water Corporation under the Ministry of Economic Planning and Budget and the Rural Water Supply and Sanitation Agency (RUWASSA) under the auspices of the State's Executive Governor's Office.

It is suggested that the hygiene behaviour of people in the communities be improved through scaling up of health education with emphasis on personal and environmental hygiene and sanitation using appropriate information, education and communication/behaviour change and communication (IEC/ BCC) strategies targeted at school aged children, women who are mainly care-givers and home keepers and special occupational groups that include those who engage in fishing and sand mining in rivers given results presented in Table 4 that showed that over half of respondents go to streams/rivers where they could easily be infected and or re-infected. This is equally important as it is evident in Table 3 that showed the poor and unsafe ways adopted in disposing faeces, knowing that though a larger number of the respondents knew that passing of urine or defaecating in the river or stream could contaminate the environment and contribute to the spread of schistosomiasis in Table 5, about one quarter of them who were unaware of this as a way of spreading schistosomiasis could continue to put the populations at risk of infection out of ignorance. The need to scale up health education becomes important because lack of awareness about mode of transmission of parasitic infections increases the risk of infection as reported by Nyantekyi, et al. [25].

The health education activities can be implemented through the collaboration of the State Ministries of Health, Information and Orientation and Education, Science and Technology. It is suggested that topics relating to cause, prevention and treatment of schistosomiasis are included in the school curriculum with emphasis on the importance of good hygiene and sanitation particularly at the primary level where we have children of age group identified as most at risk of the infection in Figure 3.

The fact that schistosomiasis is also an environmental problem just as it is also a health challenge suggests the need for appropriate legislation and enforcement of the law against open defecation which the people predominantly indulge in the LGAs as their way of disposing human waste as confirmed by virtually half the respondents in Table 2 .

Despite the fact that the first edition of the Integrated Disease Surveillance and Response (IDSR) in the African Region advocated for countries to establish Community-Based Surveillance (CBS) systems since 2001 and structures are not functional or are still to be built to detect, prevent and respond to public health events in some communities [26] such as the ones studied, the need to establish a community-based surveillance and reporting system in the communities with effective supervision and integration of such system with other major preventable diseases becomes imperative. Participation of targeted communities in the control efforts is one of the cardinal tools for the success and sustainability of disease control programmes as emphasised by Alemu, et al. [27]. The evidence of community involvement and participation only in Oke Igbo for example though is discouraging. Nonetheless, the willingness of some people in other communities to participate in the health care delivery programme if not for some constraints is encouraging and could serve as a good launchpad for successful establishment of a community-based surveillance and reporting system for effective control of schistosomiasis in communities of the LGAs.

It is encouraging that health workers were trained and involved in mass drug administration of praziquantel to pupils in schools of the study LGAs given the evidence of the effectiveness of community-based health workers in delivering health services is important in achieving universal health coverage as they can go beyond provision of care and foster community-based action [28]. The training and involvement of teachers is more encouraging in this respect and showed that a more inclusive community volunteer scheme health programme implementation in the State could be adopted based on the role of community volunteers demonstrated in supporting initiatives and programmes like intermittent preventive treatment of malaria in pregnancy and onchocerciasis [29], polio eradication, guinea worm eradication, trachoma control, integrated community case management, maternal and child health integrated programme, and early warning and response to public health emergencies in Africa [26]. Similarly, the participation of teachers and schools is very encouraging as it has successfully shown to be very useful in population coverage and health education in the control of schistosomiasis in the Gizan region of Saudi Arabia where prevalence of the predominant species, Schistosoma haematobium dropped from $43-91 \%$ to $<1 \%$ between 1974 and 1979 [30].

Given the global vector control response on integrated approach for the control of vector-borne diseases [31], it will not be out of place to advocate for the integration of the schistosomiasis treatment programme into the communitydirected treatment approach for the control of onchocerciasis [32] which is also highly endemic in Ondo State. Such integration is expected to increase efficiency, decrease the burden of health staff, improves access to treatment and improve the costeffectiveness of health spending while maintaining treatment coverage for the disease control programmes.

In view of some identified challenges including financial constraint similarly identified by Federal Ministry of Health [11] to be militating against the smooth implementation of the mass drug administration in schools as enumerated from the results, this calls for strong political will and commitment to action from the State and local governments in making the Schistosomiasis Control Programme succeed with adequate support to involve all stakeholders including all schools with children of high risk age group with financial and material resources to improve human capacities and supplies for prompt and regular surveillance and reporting, diagnosis, treatment and vector control. The need for political will and commitment is critical in ending the neglect to attaining the target of reducing the burden of NTDs by 2030 as enshrined 
in the World Health Organisation's new road map on NTDs for 2021-2030 [23] which is expected to guide countries towards the achievement of Sustainable Development Goal target 3.3 on NTDs globally [33] including the communities of the Ondo State.

The World Health Assembly resolution 54.19 of 2001 [34] stipulates that member states should ensure access to essential drugs against schistosomiasis and STHs in all health facilities in endemic areas for the treatment of clinical cases and mass drug administration for groups at high risk of clinical morbidity such as women and children, with the goal of attaining a minimum target of regular administration of chemotherapy to at least $75 \%$ and up to $100 \%$ of all school-aged children at risk of morbidity (in- and out-of-school) given that the attainment of this will greatly reduce child morbidity [35]. This could be better operationalised through the Community-Integrated Management of Childhood Illnesses (C-IMCI) strategy [36] which has three components: improving partnerships between health facilities and communities they serve; improving the technical abilities of community health workers in managing child health and increasing appropriate, accessible care and information from them; and integrated promotion of key family practices critical for child health and nutrition.

\section{Conclusion}

The findings of this study show that communities in the studied LGAs are endemic of schistosomiasis mainly because the people have little or no access to safe potable water. This increases the people's rate of contact with natural flowing streams, ponds and or rivers for domestic and occupational activities and these natural water bodies are more often than not infested with susceptible snail intermediate hosts. Other factors the study revealed to aid the transmission of schistosomiasis in the communities is lack of adequate and appropriate knowledge of the disease among the population studied and lack of political will and commitment to effective schistosomiasis control and eradication by the government. There was also evidence of poor community involvement and participation in schistosomiasis control in most of the communities studied. To eliminate schistosomiasis in communities of Ondo State in general and communities of the studied LGAs in particular knowing the fact that there is a link between schistosomiasis and poverty [37], the government at all levels need to match effective public health interventions particularly those targeting schistosomiasis management and control with socio-economic policies that foster growth and prosperity of the population.

\section{Acknowledgement}

We acknowledge the approval and cooperation of the Ondo State Ministry of Health particularly the Director for Disease Control and Primary Health Care for facilitating the success of this study. We thank the State Schistosomiasis desk officers and the Health Officers of Ifedore and Ile-Oluji/Oke Igbo local government areas for their support and involvement in this study. We also thank the community heads and people of Ipogun, Bolorunduro, Ile-Oluji and Oke Igbo communities for their cooperation. This investigation received support from the Nigerian Institute of Medical Research, Federal Ministry of Health.

\section{References}

1. Fenwick A, Webster JP (2006) Schistosomiasis; challenge for control, treatment and drug resistance. Curr Opin Infect Dis 19: 577-582. Link: https://bit.ly/3siGcsl

2. World Health Organisation (2002) Prevention and control of schistosomiasis and soil-transmitted helminthiasis. Report of an expert Committee. Geneva: World Health Organisation (WHO Technical Report Series No. 912). Link: https://bit.ly/32fCUMg

3. De Castro CCB, Dias MM, de Rezende TP, Megalhaes GL, da Silva Filho AA (2013) Chapter 8 - Natural products with activity against schistosma species. In: Rai MK, Kon KV (Eds.). Fighting multi-drug resistance with herbal extracts, essential oils and their components. Cambridge: Academic Press 109-1134. Link: https://bit.ly/3sbRmzy

4. World Health Organisation (2010) Working to overcome the global impact of neglected tropical diseases: first WHO report on neglected tropical diseases. Geneva: World Health Organisation. Link: https://bit.ly/3gaftMM

5. Hotez PJ, Kamath A (2009) Neglected tropical diseases in sub-Saharan Africa: Review of their prevalence, distribution, and disease burden. PLoS Negl Trop Dis 3: e412. Link: https://bit.ly/2Rq9d98

6. Chitsulo L (2009) WHO strategy for schistosomiasis control in sub-Saharan Africa, challenges and opportunities. A paper delivered at the Review Meeting of the Carter Centre assisted Health Programmmes, Abuja.

7. Chitsulo L, Engels D, Montressor A, Savioli L (2000) The globa status of schistosomiasis and its control. Acta Trop 77: 41-51. Link: https://bit.ly/3a6lkic

8. Vennervald BJ, Booth M, Butterworth AE, Kariuki HC, Kadzo H, et al. (2005) Regression of hepatosplenomegaly in Kenyan school-aged children after praziquantel treatment and three years of greatly reduced exposure to schistosoma mansoni. Trans R Soc Trop Med Hyg 99: 150-160. Link: https://bit.ly/32d5uOv

9. Babamale OA, Kolawole OH, Abdulganiyu K, Abdulkareem OA, Ugbomoiko US (2018) Urogenital schistosomiasis among school children and the associated risk factors in selected rural communities of Kwara State, Nigeria. J Trop Med 6913918: 1-6. Link: https://bit.ly/3sfP4PV

10. Abdulkadir A, Ahmed M, Abubakar BM, Suleiman IE, Yusuf I, et al. (2017) Prevalence of urinary schistosomiasis in Nigeria, 1994-2015: systematic review and meta-analysis. African Journal of Urology 23: 228-239. Link: https://bit.ly/3uQOPhA

11. Federal Ministry of Health (1997) National plan of action in schistosomiasis control in Nigeria, 1997-2001. Abuja, Nigeria: Federal Ministry of Health.

12. Njepuome NA, Hopkins DR, Richards FO, Anagbogu IN, Pearce PO, et al. (2009) Nigeria's war on terror: fighting dracunculiasis, onchocerciasis, lymphatic filariasis and schistosomiasis at the crossroads. Am J Trop Med Hyg 80: 691698. Link: https://bit.ly/3dgFSqj

13. National Bureau of Statistics (2009) Annual abstract of statistics 2009: Federal Republic of Nigeria. Abuja: National Bureau of Statistics. Link https://bit.ly/3e31HzE

14. Odaibo AB, Adewunmi CO, Adewoyin FB, Olofintoye LK, Adewunmi TA, et al. (2004) Preliminary studies on the prevalence and distribution of urinary schistosomiasis in Ondo State, Nigeria. Afr J Med Med Sci 33: 219-224. Link: https://bit.ly/32fwhd1

15. Oniya MO, Odaibo AB (2006) Reinfection pattern and predictors of urinary schistosomiasis among school pupils from a southwestern village in 
Nigeria. International Journal of Tropical Medicine 1: 173-176. Link: https://bit.ly/32cYEZg

16. Oniya MO, Olofintoye LK (2008) The epidemiology of urinary schistosomiasis in two endemic Local Government Areas in Ondo State, Nigeria: a report of the survey of urinary schistosomiaisis among school aged pupils in Ifedore and Ile-Oluji/Oke Igbo Local Government Areas in Ondo State, June.

17. Olofintoye LK, Odaibo AB (2005) Human water contact activities in the schistosomiasis endemic areas of Ondo and Ekiti States, Nigeria. Journal of Applied Sciences 8: 4994-5005.

18. Lwanga SK, Lemeshow S (1991) Sample size determination in health studies: A practical manual. Geneva: World Health Organisation. Link: https://bit.ly/2Q3SgRI

19. Centers for Disease Control and Prevention (1994) Epi Info [computer program]. Version 6. Atlanta: Centers for Disease Control and Prevention. Link:

20. Miles MB, Huberman AM (1994) Qualitative Data Analysis: An Expanded Sourcebook (2nd edition). London: Sage Publications. Link: https://bit.ly/3txgUZe

21. Fielding NG, Lee RM (1998) Computer Analysis and Qualitative Research London: Sage Publications.

22. Adeneye AK, Mafe MA, Appelt B, Idowu ET, Akande DO (2006) Willingness to pay for praziquantel treatment in a hyper-endemic community of Ogun State, Nigeria. Res Social Adm Pharm 2: 83-95. Link: https://bit.ly/32e4IRt

23. World Health Organisation (2020) Ending the neglect to attain the Sustainable Development Goals: a road map for neglected tropical diseases 2021-2030. Geneva: World Health Organisation. Link: https://bit.ly/2Q3Subw

24. World Health Organisation (2009) Temephos in drinking-water: use for vector control in drinking-water sources and containers. Geneva: World Health Organization (WHO/HSE/WSH/09.01/1). Link: https://bit.ly/3uSficZ

25. Nyantekyi LA, Legesse M, Belay M, Tadesse K, Manaye K, et al. (2010) Intestina parasitic infections among under-five children and maternal awareness about the infections in Shesha Kekele, Wondo Genet, Southern Ethiopia. Ethiopia Journal of Health Development 24: 185-190. Link: https://bit.ly/3djjjRJ

26. World Health Organisation (2014) Integrated disease surveillance and response in the African region a guide for establishing community based surveillance. Brazzaville: World Health Organisation, Regional Office for Africa. Link: https://bit.ly/3gbqSf3

27. Alemu A, Alemu A, Esmael N, Dessie Y, Hamdu K, et al. (2013) Knowledge, attitude and practices related to visceral leishmaniasis among residents in Addis Zemen town, South Gondar, Northwest Ethiopia. BMC Public Health 13: 382. Link: https://bit.ly/3djjgp5

28. Tulenko K, Mogedal S, Afzal MM, Frymus D, Oshin A, et al. (2013) Community health workers for universal health care coverage: from fragmentation to synergy. Bull World Health Organ 91: 841-852. Link: https://bit.ly/32cZpl4

29. Ndyomugyenyi R, Tukesiga E, Katamanywa J (2009) Intermittent preventive treatment of malaria in pregnancy (IPTp): participation of communitydirected distributors of ivermectin for onchocerciasis improves IPTp access in Ugandan rural communities. Transactions of the Royal Society of Tropical Medicine and Hygiene 102: 1221-1228. Link: https://bit.ly/3aede7f

30. Ageel AR, Amin MA (1997) Integration of schistosomiasis control activities into primary health-care system in the Gizan region, Saudi Arabia. Ann Trop Med Parasitol 91: 907-915. Link: https://bit.ly/20VkKg0
31. World Health Organisation (2017) Global vector control response: an integrated approach for the control of vector-borne diseases. Geneva: World Health Organisation (Seventieth World Health Assembly WHA70.16). Link: https://bit.ly/2RCBiKE

32. African Programme for Onchocerciasis Control (2007) Revitalising health care delivery in sub-Saharan Africa: the potential of community-directed interventions to strengthen health systems. Ouogadougou: African Programme for Onchocerciasis Control. Link: https://bit.ly/3afbXNo

33. Lee H, Pollitzer E (2016) The Role of Gender-based Innovations for the UN Sustainable Development Goals: Toward 2030: Better Science and Technology for All (Edition 1). Seoul: Korea Center for Women in Science, Engineering and Technology (WISET). Link: https://bit.ly/20S5joM

34. World Health Organisation (2001) Schistosomiasis and soil-transmitted helminth infections. Geneva: World Health Organisation (Fifty-Fourth World Health Assembly WHA54.19).

35. WHA54.19 Schistosomiasis and soil-transmitted helminth infections. Link: https://bit.ly/3tlahJH

36. National Planning Commission (NPC) [Nigeria] (2005) Nigeria: Millinenium Development Goals (2005 Report). Abuja: National Planning Commission.

37. Rosale A (2003) Community-integrated management of childhood illness (C-IMCI Handbook). Baltimore MD, USA: Catholic Relief Services.

38. Manderson L, Aagaard-Hansen J, Allotey P, Gyapong M, Sommerfeld J (2009) Social research on neglected diseases of poverty: continuing and emerging themes. PLoS Negl Trop Dis 3: e332. Link: https://bit.ly/3x77Cpk

\section{Discover a bigger Impact and Visibility of your article publication with Peertechz Publications}

\section{Highlights}

* Signatory publisher of ORCID

* Signatory Publisher of DORA (San Francisco Declaration on Research Assessment)

- Articles archived in worlds' renowned service providers such as Portico, CNKI, AGRIS, TDNet, Base (Bielefeld University Library), CrossRef, Scilit, J-Gate etc.

* Journals indexed in ICMJE, SHERPA/ROMEO, Google Scholar etc.

- OAI-PMH (Open Archives Initiative Protocol for Metadata Harvesting)

* Dedicated Editorial Board for every journal

* Accurate and rapid peer-review process

* Increased citations of published articles through promotions

* Reduced timeline for article publication

Submit your articles and experience a new surge in publication services (https://www.peertechz.com/submission).

Peertechz journals wishes everlasting success in your every endeavours.

Copyright: @ 2021 Adeneye AK, et al. This is an open-access article distributed under the terms of the Creative Commons Attribution License, which permits unrestricted use, distribution, and reproduction in any medium, provided the original author and source are credited.

Citation: Adeneye AK, Sulyman MA, Akande DO, Mafe MA (2021) Factors promoting schistosomiasis infection in endemic rural communities of Ifedore and Ile-Oluji/ Oke Igbo local government areas in Ondo State, Nigeria. Glob J Infect Dis Clin Res 7(1): 021-032. DOI: https://doi.org/10.17352/2455-5363.000042 